\title{
МАТРИЧНЫЙ МЕТОД ОЦЕНКИ УРОВНЯ ОТНОСИТЕЛЬНОЙ ЭФФЕКТИВНОСТИ ИЕРАРХИЧЕСКОЙ СИСТЕМЫ БИЗНЕС-ПРОЦЕССОВ В ОРГАНИЗАЦИИ
}

\author{
Романенков Ю.А. ${ }^{1}$, Зейниев Т.Г. ${ }^{1}$ \\ ${ }^{1}$ Национальный аэрокосмический университет им. Н.Е. Жуковского \\ «Харьковский авиационный институт», Харьков
}

Copyright (C) 2014 by author and the journal “Automation technological and business - processes”. This work is licensed under the Creative Commons Attribution International License (CC BY). http://creativecommons.org/licenses/by/4.0/

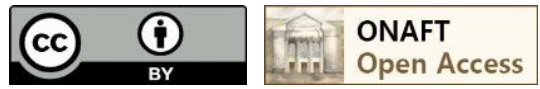

DOI: $10.15673 / 2312-3125$.

\begin{abstract}
Аннотация
Предложен матричный метод оценки уровня относительной эффективности иерархической системы бизнеспроцессов в организации, формализующий иерархическую структуру бизнес-процессов, и позволяющий оценивать эффективность структуры любого порядка и размерности. Матричная аналитическая форма предложенного метода позволяет проводить анализ эффективности бизнес-процессов в организации с помощью специализированных пакетов символьной математики для решения задач стратегического управления, а также оценивать робастность компонент эффективности к вариациям экспертных оценок. Предложенный метод проиллюстрирован численным примером.
\end{abstract}

\begin{abstract}
Matrix approach to estimation of relative efficiency level of hierarchical system of business processes in a company formalizing hierarchical structure of business processes and providing with efficiency estimation of a structure of any form and size is offered. The matrix analytical form of the offered method gives possibility to make effectiveness analysis of business processes in a company by means of a specialized package of symbol Math to solve strategic tasks as well as to estimate robustness of efficiency to variations in expert assessments. The offered method is illustrated by numerical example.
\end{abstract}

Ключевые слова

Эффективность бизнес-процессов, иерархическая относительная экспертная оценка.

Введение. Особенности экономической ситуации, в которой приходится функционировать современным предприятиям и организациям, обуславливают необходимость углубленного развития вопросов адаптации и устойчивости бизнес-процессов в организации, поддержки достаточного уровня эффективности и стабильности функционирования в неопределенных условиях рынка [1]. Оценка эффективности внутренней структуры и функциональных областей организации - одна из важных задач стратегического управления, решение которой позволяет обеспечить единой информационной метрикой контур стратегического управления организацией.

Анализ последних исследований и публикаций. Несмотря на широкий интерес к проблеме управления эффективностью бизнес-процессов в организации, данное научное направление находится на стадии формирования и характеризуется наличием широкого круга дискуссионных вопросов, связанных со становлением терминологического аппарата, с раскрытием взаимосвязей организационных способностей, компетенций и прочих 


\section{$\underline{5}$ ТЕОРІЯ І ПРАКТИКА АВТОМАТИЗАЦІЇ БІЗНЕС-ПРОЦЕСІВ}

ресурсов организации [2-5]. Актуальным является вопрос формализации задач и принципов управления, относящихся к контуру управления эффективностью бизнес-процессов в организации. Одной из таких задач является количественная оценка уровня эффективности иерархической системы бизнес-процессов в организации для обоснованного распределения ресурсов организации на управление отдельными бизнес-процессами организации.

Постановка задачи. Разработка метода относительной оценки эффективности бизнес-процессов в организации с целью обеспечения информационной базы для разработки управленческих решений является актуальной научнопрактической задачей, решение которой расширит методическое и информационное обеспечение процесса принятия управленческих решений в контуре стратегического управления эффективностью бизнес-процессов в организации.

Основная часть. Схема контура стратегического управления эффективностью бизнес-процессов в организации представлена на рис. 1. Обозначения на рис. 1: $X_{1}, X_{2}, \ldots, X_{n}$ - вектора-строки, отражающие уровень эффективности $n$ бизнес-процессов организации; $\mathbf{X}_{0}$ - составная матрица из векторов $X_{1}, X_{2}, \ldots, X_{n} ; \mathbf{X}_{1}, \mathbf{X}_{2}$, $\ldots, \mathbf{X}_{m}$ - матрицы, сформированные аналогично $\mathbf{X}_{0}$ и содержащие данные о конкурентах базового объекта (организации) общим количеством $m ; \mathbf{X}_{\text {max }}-$ эталонная модель; $\mathbf{X}^{*}=\mathbf{X}_{\max }-\mathbf{X}_{0}$ - матрица разрывов; $Q-$ вектор ресурсов; $U_{1}, U_{2}, \ldots, U_{n}$ - вектора управляющих воздействий на бизнес-процессы; $\mathbf{U}$ - составная управляющая матрица из векторов $U_{1}, U_{2}, \ldots, U_{n}$.

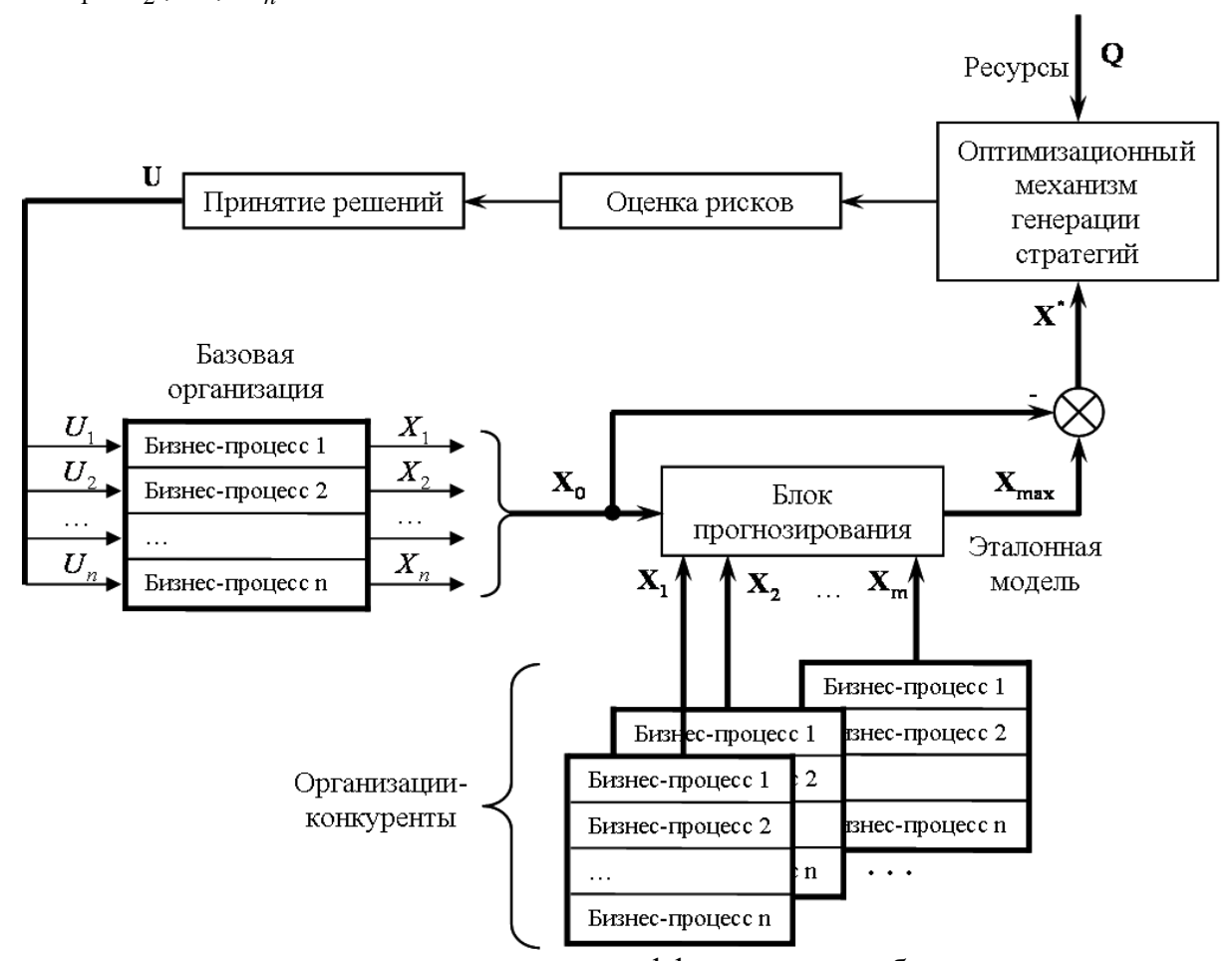

Рис. 1. Схема контура стратегического управления эффективностью бизнес-процессов в организации

Объект управления (базовая организация) характеризуется набором векторов $X_{1}, X_{2}, \ldots, X_{n}$, отражающих уровень эффективности $n$ бизнес-процессов организации, каждый из которых состоит из компонент относительных показателей эффективности соответствующего бизнес-процесса:

$$
X_{1}=\left[x_{11}, x_{12}, \ldots, x_{1 l_{1}}\right], X_{2}=\left[x_{21}, x_{22}, \ldots, x_{2 l_{2}}\right], \ldots, X_{n}=\left[x_{n 1}, x_{n 2}, \ldots, x_{n l_{n}}\right],
$$

где $l_{1}, l_{2}, \ldots, l_{n}$ - размерности векторов $X_{1}, X_{2}, \ldots, X_{n}$.

Компонента $x_{i j}$ представляет собой относительную эффективность $j$-й компоненты $i$-го бизнес-процесса, и оценивается экспертами путем сравнения с аналогичными бизнес-процессами организаций-конкурентов. 


\section{$\underline{5}$ ТЕОРІЯ I ПРАКТИКА АВТОМАТИЗАЦІЇ БІЗНЕС-ПРОЦЕСІВ}

Исходя из сущности показателей $x_{i j}$, область их допустимых значений ограничен интервалом $x_{i j} \in[0,1]$, хотя может быть и иной, в зависимости от шкалы оценивания, выбранной экспертами. Единица соответствует максимальной эффективности $j$-й компоненты $i$-го бизнес-процесса среди группы оцениваемых организаций.

Набор векторов (1) может быть представлен в виде составной матрицы $\mathbf{X}_{0}$ следующей структуры

$$
\mathbf{X}_{0}=\left[\begin{array}{llllll}
{\left[X_{1}\right.} & ] & 0 & 0 & \ldots & 0 \\
{[} & X_{2} & ] & 0 & \ldots & 0 \\
\ldots & & & & & \\
{[} & & X_{k} & & &
\end{array}\right],
$$

где $X_{k}$ - вектор максимальной размерности из набора $X_{1}, X_{2}, \ldots, X_{n}, l_{k}=\max _{i=1}^{n}\left\{l_{i}\right\}$.

Матрицы $\mathbf{X}_{1}, \mathbf{X}_{2}, \ldots, \mathbf{X}_{m}$ содержат данные о конкурентах базового объекта (организации), общим количеством $m$, и формируются аналогично $\mathbf{X}_{0}$. Полная группа рассматриваемых организаций, включая базовую организацию и ее конкурентов, функционирует внутри отрасли или профессионального направления, которое может быть охарактеризовано относительными коэффициентами значимости (рис. 2).

Пусть каждый из $n$ бизнес-процессов в организации характеризуется вектором-столбцом коэффициентов относительной значимости компонент бизнес-процесса

$$
A_{i}=\left[\begin{array}{llll}
\alpha_{i 1} & \alpha_{i 2} & \ldots & \alpha_{i l_{i}}
\end{array}\right]^{T}, i=1,2, \ldots, n,
$$

где $\alpha_{i j}$ - коэффициент относительной значимости $j$-й компоненты $i$-го бизнес-процесса, причем $0 \leq \alpha_{i j} \leq 1$, $\sum_{j=1}^{l_{i}} \alpha_{i j}=1, i=1,2, \ldots, n$.

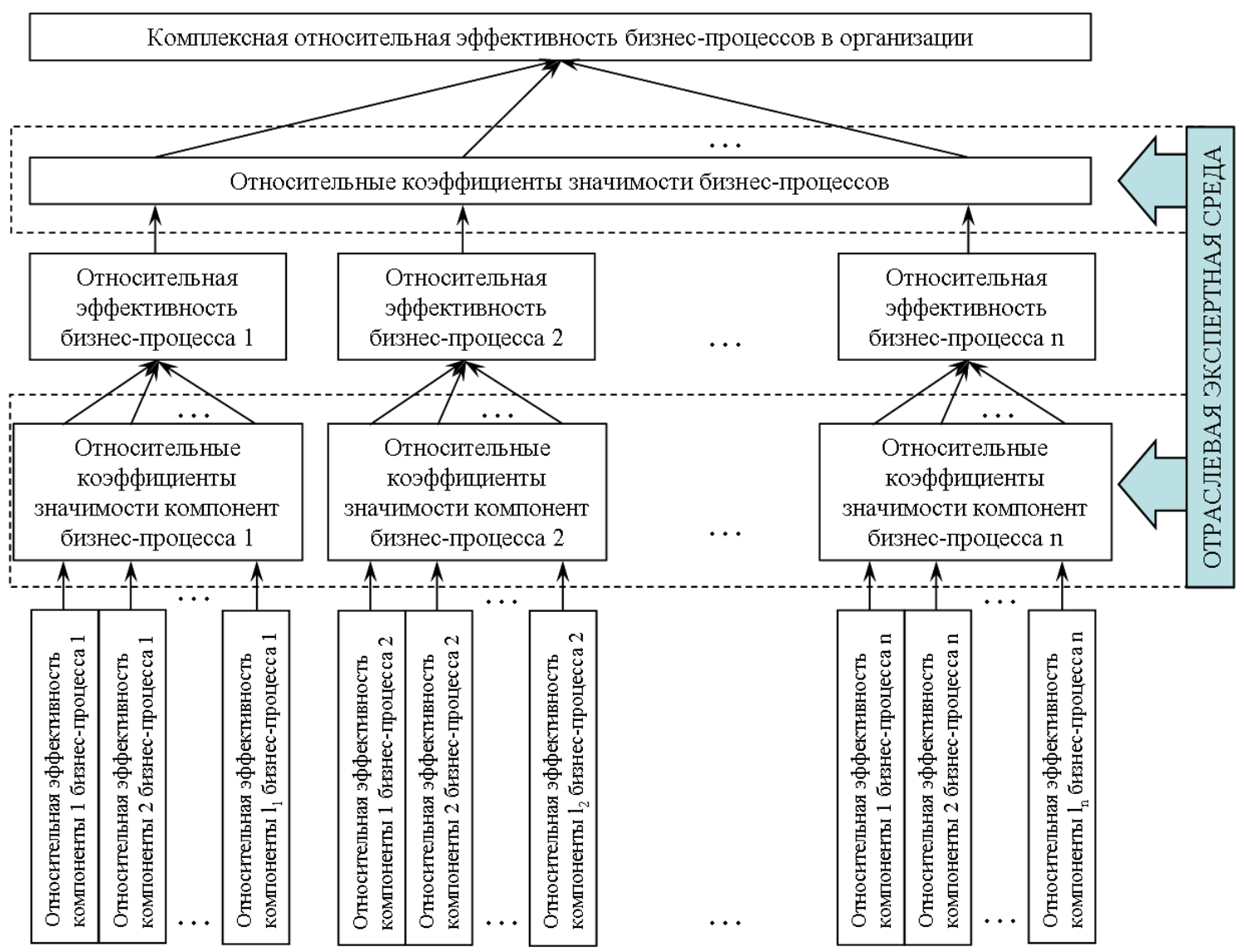

Рис. 2. Иерархическая структура экономической эффективности бизнес-процессов в организации 


\section{$\underline{5}$ ТЕОРІЯ І ПРАКТИКА АВТОМАТИЗАЦІЇ БІЗНЕС-ПРОЦЕСІВ}

Набор векторов (4) может быть представлен в виде составной матрицы $\mathbf{A}$, составленной аналогично $\mathbf{X}_{0}$ :

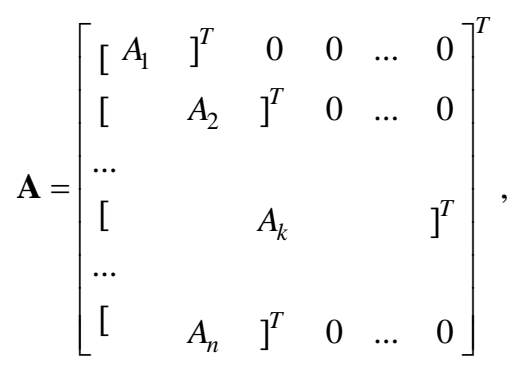

где $A_{k}$ - вектор максимальной размерности из набора (4).

Произведение матриц $\mathbf{X}_{0} \mathbf{A}$ - квадратная матрица размером $n \times n$, которая содержит в главной диагонали относительную эффективность $n$ бизнес-процессов в организации:

$$
\mathbf{X}_{0} \mathbf{A}=\left[\begin{array}{cccc}
X_{1} A_{1} & X_{1} A_{2} & \ldots & X_{1} A_{n} \\
X_{2} A_{1} & X_{2} A_{2} & \ldots & X_{2} A_{n} \\
\ldots & \ldots & \ldots & \ldots \\
X_{n} A_{1} & X_{n} A_{2} & \ldots & X_{n} A_{n}
\end{array}\right]
$$

Определим В как матрицу размером $n \times n$, содержащую в главной диагонали относительные коэффициенты значимости бизнес-процессов

$$
B=\left[\begin{array}{cccccc}
\beta_{1} & 0 & 0 & \ldots & 0 & 0 \\
0 & \beta_{2} & 0 & \ldots & 0 & 0 \\
\ldots & & & & & \\
& & & & & \\
0 & 0 & 0 & \ldots & \beta_{n-1} & 0 \\
0 & 0 & 0 & \ldots & 0 & \beta_{n}
\end{array}\right],
$$

где $\beta_{i}$ - относительный коэффициент значимости $i$-го бизнес-процесса в организации, причем $0 \leq \beta_{i} \leq 1$, $\sum_{i=1}^{n} \beta_{i}=1, i=1,2, \ldots, n$.

Матрица $\mathbf{X}_{0} \mathbf{A B}$ содержит в главной диагонали взвешенные относительные эффективности всех бизнеспроцессов в организации:

$$
\mathbf{X}_{0} \mathbf{A B}=\left[\begin{array}{cccc}
\beta_{1} X_{1} A_{1} & \beta_{2} X_{1} A_{2} & \ldots & \beta_{n} X_{1} A_{n} \\
\beta_{1} X_{2} A_{1} & \beta_{2} X_{2} A_{2} & \ldots & \beta_{n} X_{2} A_{n} \\
\ldots & \ldots & \ldots & \ldots \\
\beta_{1} X_{n} A_{1} & \beta_{2} X_{n} A_{2} & \ldots & \beta_{n} X_{n} A_{n}
\end{array}\right]
$$

Комплексную относительную эффективность бизнес-процессов в организации можно найти, определив след матрицы $\mathbf{X}_{0} \mathbf{A B}$ :

$$
E=\operatorname{tr}\left(\mathbf{X}_{0} \mathbf{A B}\right)=\beta_{1} X_{1} A_{1}+\beta_{2} X_{2} A_{2}+\ldots+\beta_{n} X_{n} A_{n}=\sum_{i=1}^{n} \beta_{i} X_{i} A_{i} .
$$

Таким образом, предложен матричный метод оценки уровня относительной эффективности иерархической системы бизнес-процессов в организации, формализующий иерархическую структуру эффективности бизнеспроцессов, и за счет матричной аналитической формы позволяющий оценивать эффективность структуры любого порядка и размерности. 


\section{$\underline{5}$ ТЕОРІЯ I ПРАКТИКА АВТОМАТИЗАЦІЇ БІЗНЕС-ПРОЦЕСІВ}

Пример. Глобальная система бизнес-процессов организации может быть представлена 10 бизнес-процессами [6] (табл. 1).

Таблица 1 - Система бизнес-процессов организации и относительные коэффициенты значимости

\begin{tabular}{|c|l|c|}
\hline$i$ & \multicolumn{1}{|c|}{ Бизнес-процесс } & Относительные коэффициенты значимости $\beta_{i}$ \\
\hline 1 & организационная структура управления & 0,07 \\
\hline 2 & система управления & 0,12 \\
\hline 3 & маркетинг & 0,15 \\
\hline 4 & система организации производства & 0,13 \\
\hline 5 & персонал предприятия & 0,06 \\
\hline 6 & НИОКР & 0,1 \\
\hline 7 & финансы & 0,09 \\
\hline 8 & снабжение & 0,1 \\
\hline 9 & сбыт & 0,11 \\
\hline 10 & учет & 0,07 \\
\hline
\end{tabular}

Иерархическая структура компонентов бизнес-процессов, их относительная эффективность, а также относительные коэффициенты значимости представлены в табл. 2.

Таблица 2 - Иерархическая структура компонентов бизнес-процессов

\begin{tabular}{|c|c|c|c|}
\hline $\begin{array}{l}\text { Бизнес- } \\
\text { процесс }\end{array}$ & Компоненты бизнес-процесса & $\begin{array}{l}\text { Относительная } \\
\text { эффективность } \\
\text { компоненты } x_{i j}\end{array}$ & $\begin{array}{c}\text { Относительный } \\
\text { коэффициент } \\
\text { значимости } \\
\text { компоненты } \alpha_{i j}\end{array}$ \\
\hline \multirow{4}{*}{$\begin{array}{c}1 . \\
\text { Организацион } \\
\text { ная структура }\end{array}$} & $\begin{array}{l}1.1 \text { Степень соответствия плана структуры условиям ее } \\
\text { функционирования }\end{array}$ & 0,9 & 0,25 \\
\hline & 1.2 Численность работников управления & 0,8 & 0,15 \\
\hline & $\begin{array}{l}1.3 \text { Степень адекватности распределения работников } \\
\text { управления по уровням и функциям }\end{array}$ & 0,8 & 0,25 \\
\hline & 1.4 Качество информационных связей & 0,9 & 0,35 \\
\hline \multirow{6}{*}{$\begin{array}{l}\text { 2. Система } \\
\text { управления }\end{array}$} & $\begin{array}{l}2.1 \text { Опыт, квалификация и кругозор руководства } \\
\text { организации в управленческой деятельности }\end{array}$ & 0,9 & 0,16 \\
\hline & $\begin{array}{l}2.2 \text { Общее мнение о топ-менеджерах организации как } \\
\text { о партнерах в деловых кругах }\end{array}$ & 0,8 & 0,13 \\
\hline & 2.3 Система стратегического планирования & 1 & 0,20 \\
\hline & $\begin{array}{l}2.4 \text { Способность быстро реагировать на меняющуюся } \\
\text { рыночную ситуацию }\end{array}$ & 0,8 & 0,20 \\
\hline & 2.5 Уровень информационных систем & 0,8 & 0,16 \\
\hline & 2.6 Степень организации функций управления & 0,8 & 0,15 \\
\hline \multirow[t]{6}{*}{ 3. Маркетинг } & 3.1 Система организации маркетинга & 1 & 0,18 \\
\hline & 3.2 Система исследования рынка & 0,9 & 0,18 \\
\hline & 3.3 Ассортиментная политика & 0,8 & 0,16 \\
\hline & 3.4 Ценовая политика & 0,8 & 0,16 \\
\hline & 3.5 Коммуникационная политика & 0,7 & 0,16 \\
\hline & 3.6 Распределительная политика & 0,8 & 0,16 \\
\hline \multirow{8}{*}{\begin{tabular}{|c|} 
4. Система \\
организации \\
производства
\end{tabular}} & 4.1 Численность занятых в производстве & 0,8 & 0,10 \\
\hline & 4.2 Основные используемые технологии & 0,8 & 0,12 \\
\hline & 4.3 Инновации в производственном процессе & 0,8 & 0,12 \\
\hline & 4.4 Степень овладения существующими технологиями & 0,8 & 0,13 \\
\hline & 4.5 Технико-технологическая база предприятия & 0,9 & 0,15 \\
\hline & 4.6 Система планирования производства & 0,8 & 0,14 \\
\hline & 4.7 Система обеспечения качество продукции & 0,8 & 0,14 \\
\hline & 4.8 Производительность труда & 0,7 & 0,10 \\
\hline
\end{tabular}




\section{$\underline{5}$ ТЕОРІЯ І ПРАКТИКА АВТОМАТИЗАЦІЇ БІЗНЕС-ПРОЦЕСІВ}

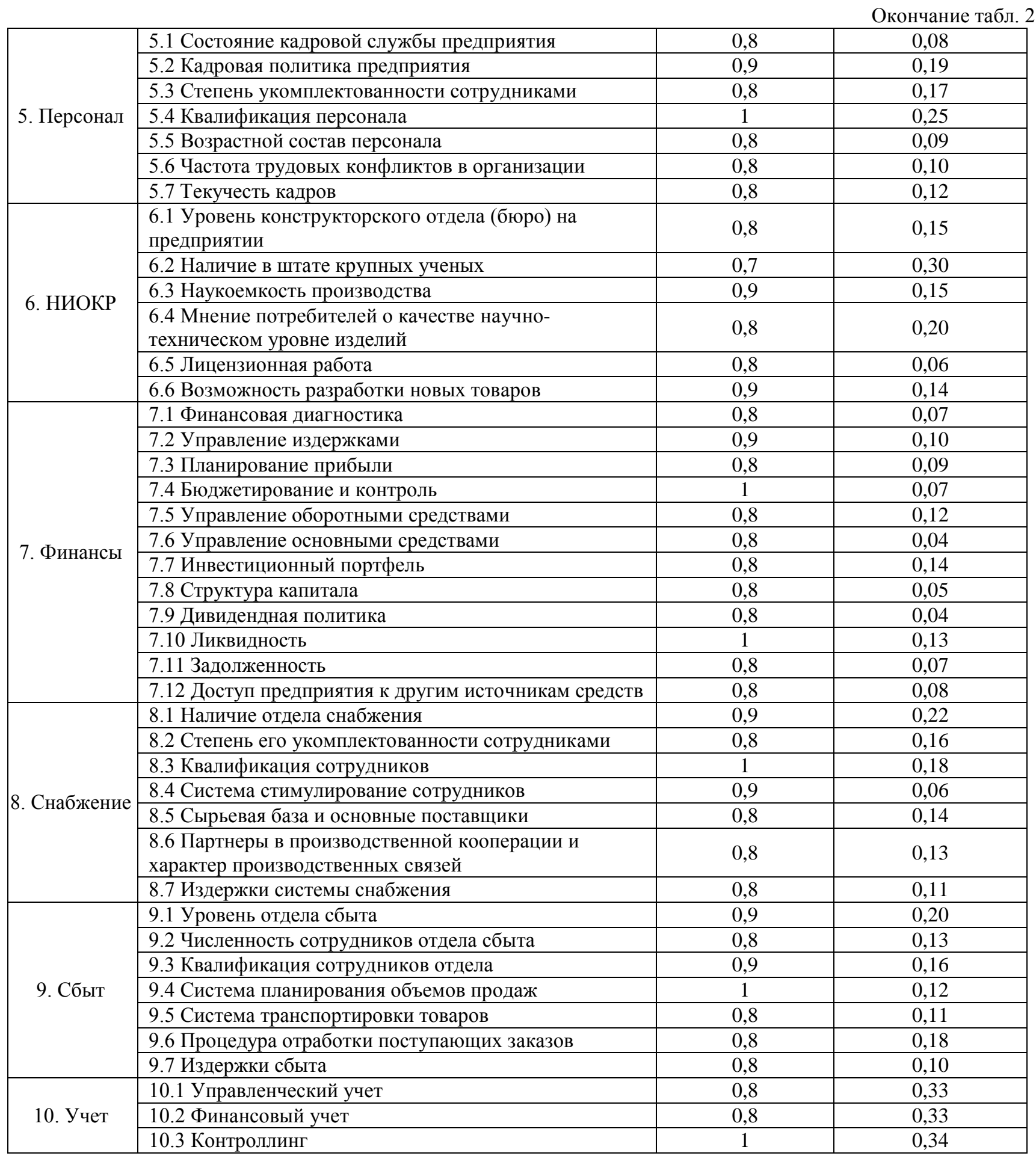




\section{$\underline{5}$ ТЕОРІЯ І ПРАКТИКА АВТОМАТИЗАЦІЇ БІЗНЕС-ПРОЦЕСІВ}

Сформируем на основании данных из табл. 1 согласно (6) матрицу В :

$$
B=\left[\begin{array}{cccccccccc}
0,07 & 0 & 0 & 0 & 0 & 0 & 0 & 0 & 0 & 0 \\
0 & 0,12 & 0 & 0 & 0 & 0 & 0 & 0 & 0 & 0 \\
0 & 0 & 0,15 & 0 & 0 & 0 & 0 & 0 & 0 & 0 \\
0 & 0 & 0 & 0,13 & 0 & 0 & 0 & 0 & 0 & 0 \\
0 & 0 & 0 & 0 & 0,06 & 0 & 0 & 0 & 0 & 0 \\
0 & 0 & 0 & 0 & 0 & 0,1 & 0 & 0 & 0 & 0 \\
0 & 0 & 0 & 0 & 0 & 0 & 0,09 & 0 & 0 & 0 \\
0 & 0 & 0 & 0 & 0 & 0 & 0 & 0,1 & 0 & 0 \\
0 & 0 & 0 & 0 & 0 & 0 & 0 & 0 & 0,11 & 0 \\
0 & 0 & 0 & 0 & 0 & 0 & 0 & 0 & 0 & 0,07
\end{array}\right] .
$$

На основании данных из табл. 2 сформируем согласно (1) и (3) векторы $X_{i}$ и $A_{i}$ :

$$
\begin{aligned}
& X_{1}=\left[\begin{array}{llll}
0,9 & 0,8 & 0,8 & 0,9
\end{array}\right], X_{2}=\left[\begin{array}{llllll}
0,9 & 0,8 & 1 & 0,8 & 0,8 & 0,8
\end{array}\right], X_{3}=\left[\begin{array}{llllll}
1 & 0,9 & 0,8 & 0,8 & 0,7 & 0,8
\end{array}\right] \text {, } \\
& X_{4}=\left[\begin{array}{llllllll}
0,8 & 0,8 & 0,8 & 0,8 & 0,9 & 0,8 & 0,8 & 0,7
\end{array}\right], X_{5}=\left[\begin{array}{lllllll}
0,8 & 0,9 & 0,8 & 1 & 0,8 & 0,8 & 0,8
\end{array}\right], \\
& X_{6}=\left[\begin{array}{llllll}
0,8 & 0,7 & 0,9 & 0,8 & 0,8 & 0,9
\end{array}\right], X_{7}=\left[\begin{array}{lllllllllllll}
0,8 & 0,9 & 0,8 & 1 & 0,8 & 0,8 & 0,8 & 0,8 & 0,8 & 1 & 0,8 & 0,8
\end{array}\right] \text {, } \\
& X_{8}=\left[\begin{array}{lllllll}
0,9 & 0,8 & 1 & 0,9 & 0,8 & 0,8 & 0,8
\end{array}\right], X_{9}=\left[\begin{array}{lllllll}
0,9 & 0,8 & 0,9 & 1 & 0,8 & 0,8 & 0,8
\end{array}\right], X_{10}=\left[\begin{array}{lll}
0,8 & 0,8 & 1
\end{array}\right] ; \\
& A_{1}=\left[\begin{array}{llll}
0,25 & 0,15 & 0,25 & 0,35
\end{array}\right]^{T}, A_{2}=\left[\begin{array}{llllll}
0,16 & 0,13 & 0,2 & 0,2 & 0,16 & 0,15
\end{array}\right]^{T},
\end{aligned}
$$

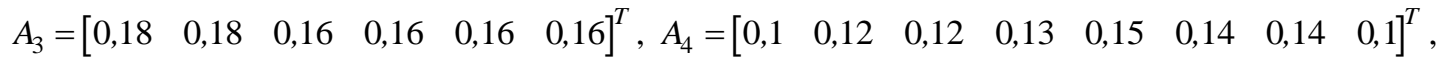

$$
\begin{aligned}
& A_{5}=\left[\begin{array}{lllllll}
0,08 & 0,19 & 0,17 & 0,25 & 0,09 & 0,1 & 0,12
\end{array}\right]^{T}, A_{6}=\left[\begin{array}{llllll}
0,15 & 0,3 & 0,15 & 0,2 & 0,06 & 0,14
\end{array}\right]^{T},
\end{aligned}
$$

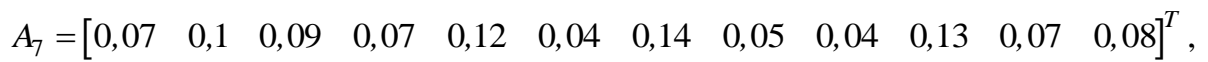

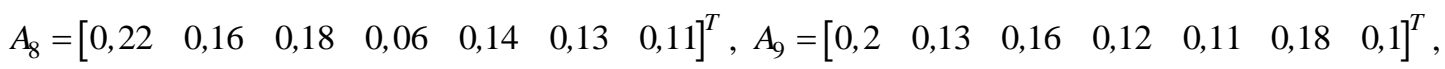

$$
\begin{aligned}
& A_{10}=\left[\begin{array}{lll}
0,33 & 0,33 & 0,34
\end{array}\right]^{T} \text {. }
\end{aligned}
$$

Сформируем из них матрицы $\mathbf{X}_{0}$ и $\mathbf{A}$ согласно (2) и (4):

$$
\mathbf{X}_{0}=\left[\begin{array}{cccccccccccc}
0,9 & 0,8 & 0,8 & 0,9 & 0 & 0 & 0 & 0 & 0 & 0 & 0 & 0 \\
0,9 & 0,8 & 1 & 0,8 & 0,8 & 0,8 & 0 & 0 & 0 & 0 & 0 & 0 \\
1 & 0,9 & 0,8 & 0,8 & 0,7 & 0,8 & 0 & 0 & 0 & 0 & 0 & 0 \\
0,8 & 0,8 & 0,8 & 0,8 & 0,9 & 0,8 & 0,8 & 0,7 & 0 & 0 & 0 & 0 \\
0,8 & 0,9 & 0,8 & 1 & 0,8 & 0,8 & 0,8 & 0 & 0 & 0 & 0 & 0 \\
0,8 & 0,7 & 0,9 & 0,8 & 0,8 & 0,9 & 0 & 0 & 0 & 0 & 0 & 0 \\
0,8 & 0,9 & 0,8 & 1 & 0,8 & 0,8 & 0,8 & 0,8 & 0,8 & 1 & 0,8 & 0,8 \\
0,9 & 0,8 & 1 & 0,9 & 0,8 & 0,8 & 0,8 & 0 & 0 & 0 & 0 & 0 \\
0,9 & 0,8 & 0,9 & 1 & 0,8 & 0,8 & 0,8 & 0 & 0 & 0 & 0 & 0 \\
0,8 & 0,8 & 1 & 0 & 0 & 0 & 0 & 0 & 0 & 0 & 0 & 0
\end{array}\right],
$$




\section{$\underline{5}$ ТЕОРІЯ І ПРАКТИКА АВТОМАТИЗАЦІЇ БІЗНЕС-ПРОЦЕСІВ}

$$
\mathbf{A}=\left[\begin{array}{cccccccccc}
0,25 & 0,16 & 0,18 & 0,1 & 0,08 & 0,15 & 0,07 & 0,22 & 0,2 & 0,33 \\
0,15 & 0,13 & 0,18 & 0,12 & 0,19 & 0,3 & 0,1 & 0,16 & 0,13 & 0,33 \\
0,25 & 0,2 & 0,16 & 0,12 & 0,17 & 0,15 & 0,09 & 0,18 & 0,16 & 0,34 \\
0,35 & 0,2 & 0,16 & 0,13 & 0,25 & 0,2 & 0,07 & 0,06 & 0,12 & 0 \\
0 & 0,16 & 0,16 & 0,15 & 0,09 & 0,06 & 0,12 & 0,14 & 0,11 & 0 \\
0 & 0,15 & 0,16 & 0,14 & 0,1 & 0,14 & 0,04 & 0,13 & 0,18 & 0 \\
0 & 0 & 0 & 0,14 & 0,12 & 0 & 0,14 & 0,11 & 0,1 & 0 \\
0 & 0 & 0 & 0,1 & 0 & 0 & 0,05 & 0 & 0 & 0 \\
0 & 0 & 0 & 0 & 0 & 0 & 0,04 & 0 & 0 & 0 \\
0 & 0 & 0 & 0 & 0 & 0 & 0,13 & 0 & 0 & 0 \\
0 & 0 & 0 & 0 & 0 & 0 & 0,07 & 0 & 0 & 0 \\
0 & 0 & 0 & 0 & 0 & 0 & 0,08 & 0 & 0 & 0
\end{array}\right] .
$$

Произведение матриц $\mathbf{X}_{0} \mathbf{A}$ согласно (8):

$$
\mathbf{X}_{0} \mathbf{A}=\left[\begin{array}{cccccccccc}
\mathbf{0 , 8 6} & 0,588 & 0,578 & 0,399 & 0,585 & 0,675 & 0,278 & 0,524 & 0,52 & 0,833 \\
0,875 & \mathbf{0 , 8 5 6} & 0,85 & 0,642 & 0,746 & 0,845 & 0,417 & 0,77 & 0,772 & 0,901 \\
0,865 & 0,829 & \mathbf{0 , 8 3 8} & 0,625 & 0,73 & 0,854 & 0,404 & 0,758 & 0,762 & 0,899 \\
0,8 & 0,816 & 0,816 & \mathbf{0 , 8 0 5} & 0,809 & 0,806 & 0,551 & 0,814 & 0,811 & 0,8 \\
0,885 & 0,853 & 0,85 & 0,758 & \mathbf{0 , 8 6 9} & 0,87 & 0,528 & 0,828 & 0,837 & 0,833 \\
0,81 & 0,822 & 0,814 & 0,688 & 0,712 & \mathbf{0 , 7 9 9} & 0,395 & 0,727 & 0,741 & 0,801 \\
0,885 & 0,853 & 0,85 & 0,838 & 0,869 & 0,87 & \mathbf{0 , 8 5} & 0,828 & 0,837 & 0,833 \\
0,91 & 0,876 & 0,866 & 0,767 & 0,867 & 0,865 & 0,536 & \mathbf{0 , 8 6 4} & 0,864 & 0,901 \\
0,92 & 0,876 & 0,866 & 0,768 & 0,875 & 0,87 & 0,534 & 0,852 & \mathbf{0 , 8 6} & 0,867 \\
0,57 & 0,432 & 0,448 & 0,296 & 0,386 & 0,51 & 0,226 & 0,484 & 0,424 & \mathbf{0 , 8 6 8}
\end{array}\right] .
$$

Произведение матриц $\mathbf{X}_{0} \mathbf{A B}$ согласно (12):

$$
\mathbf{X}_{0} \mathbf{A B}=\left[\begin{array}{cccccccccc}
\mathbf{0 , 0 6 0 2} & 0,07056 & 0,0867 & 0,05187 & 0,0351 & 0,0675 & 0,02502 & 0,0524 & 0,0572 & 0,05831 \\
0,06125 & \mathbf{0 , 1 0 2 7 2} & 0,175 & 0,08346 & 0,04476 & 0,0845 & 0,03753 & 0,077 & 0,08492 & 0,06307 \\
0,06055 & 0,09948 & \mathbf{0 , 1 2 5 7} & 0,08125 & 0,0438 & 0,0854 & 0,03636 & 0,0758 & 0,08382 & 0,06293 \\
0,056 & 0,0972 & 0,1224 & \mathbf{0 , 1 0 4 6 5} & 0,04854 & 0,0806 & 0,04959 & 0,0814 & 0,08921 & 0,056 \\
0,06195 & 0,10236 & 0,1275 & 0,09854 & \mathbf{0 , 0 5 2 1 4} & 0,087 & 0,04752 & 0,0828 & 0,09207 & 0,05831 \\
0,0567 & 0,09864 & 0,1221 & 0,08086 & 0,04272 & \mathbf{0 , 0 7 9 9} & 0,03555 & 0,0727 & 0,08151 & 0,05607 \\
0,06195 & 0,10236 & 0,1275 & 0,10894 & 0,05214 & 0,087 & \mathbf{0 , 0 7 6 5} & 0,0828 & 0,09207 & 0,05831 \\
0,0637 & 0,10512 & 0,1299 & 0,09971 & 0,05202 & 0,0865 & 0,04824 & \mathbf{0 , 0 8 6 4} & 0,09504 & 0,06307 \\
0,0644 & 0,10512 & 0,1299 & 0,09984 & 0,0525 & 0,087 & 0,04806 & 0,0852 & \mathbf{0 , 0 9 4 6} & 0,06069 \\
0,0399 & 0,05184 & 0,0672 & 0,03848 & 0,02316 & 0,051 & 0,02034 & 0,0484 & 0,04664 & \mathbf{0 , 0 6 0 7 6}
\end{array}\right] .
$$

Комплексная относительная эффективность бизнес-процессов в организации согласно (8):

$$
E=\operatorname{tr}\left(\mathbf{X}_{0} \mathbf{A B}\right)=0,84357 .
$$

Выводы. Предложен матричный метод оценки уровня относительной эффективности иерархической системы бизнес-процессов в организации, формализующий иерархическую структуру бизнес-процессов, и позволяющий оценивать эффективность структуры любого порядка и размерности. Матричная аналитическая форма предложенного метода позволяет проводить анализ эффективности бизнес-процессов в организации с помощью специализированных пакетов символьной математики (например, Maple) для решения задач стратегического управления. Дальнейшие исследования могут быть направлены на оценку робастности компонент эффективности к вариациям экспертных оценок. 


\section{5 ТЕОРІЯ І ПРАКТИКА АВТОМАТИЗАЦІЇ БІЗНЕС-ПРОЦЕСІВ}

\section{Литература}

1. Зуева А.Г., Носков Б.В., Сидоренко Е.В., Всяких Е.И., Киселев С.П. Практика и проблематика моделирования бизнес процессов. Под общ. ред. Треско И.А. - М.: ДМК Пресс; М.: Компания АйТи, 2008. - 246 с.: ил. (Серия «ИТ-Экономика»).;

2. Вартанян В.М. Модель і метод діагностування рівня економічної безпеки машинобудівного підприємства в умовах параметричної невизначеності /В.М. Вартянян, О.М. Скачков, Д.С. Ревенко // Вісник Національного університету Львівська політехніка. Автоматика, вимірювання та керування. - Львів: Видавництво Львівської політехніки, 2012 - №741.- с.262-265.;

3. Камишникова, Е.В. Методика оцінки рівня економічної безпеки металургічного підприємства [Текст] / Е.В. Камишникова // Актуальні проблеми економіки. Економіка та управління підприємствами: зб. наук. пр. - Вип. 11 (101). - К., 2009. - С. 77 - 82.;

4. Сорокіна, І.В. Теоретико-методологічні аспекти формування системи економічної безпеки підприємства [Текст] / І.В. Сорокіна // Актуальні проблеми економіки. Економіка та управління підприємствами: зб. наук. пр. - Вип. 12 (102). - К., 2009. - С. 114 - 122.;

5. Гавва, В.М. Обгрунтування господарських рішень і оцінювання ризиків [Текст] / В.М. Гавва, Т.П. Раздимаха. - Х.: ХАИ, 2008. - 272 с.;

6. Вартанян, В.М. Модели, методы и инструментальные средства поддержки принятия решений в наукоемком высокотехнологическом производстве [Текст]: моногр. / В.М. Вартанян, Б.Б. Стелюк, М.А. Глованова, И.В. Дронова. - Х.: ИД «ИНЖЕК», 2009. - 224с.

\section{References}

1. Zueva A.H., Noskov B.V., Sydorenko E.V., Vsyakykh E.Y., Kyselev S.P. Praktyka y problematyka modelyrovanyya byznes protsessov. Pod obshch. red. Tresko Y.A. - M.: DMK Press; M.: Kompanyya AyTy, 2008. - 246 s.: yl. (Seryya «YT-Ekonomyka»).;

2. Vartanyan V.M. Model' i metod diahnostuvannya rivnya ekonomichnoyi bezpeky mashynobudivnoho pidpryyemstva v umovakh parametrychnoyi nevyznachenosti /V.M. Vartyanyan, O.M. Skachkov, D.S. Revenko // Visnyk Natsional'noho universytetu L'vivs'ka politekhnika. Avtomatyka, vymiryuvannya ta keruvannya. - L'viv: Vydavnytstvo L'vivs'koyi politekhniky, 2012 - \#741.- s.262-265.;

3. Kamyshnykova, E.V. Metodyka otsinky rivnya ekonomichnoyi bezpeky metalurhichnoho pidpryyemstva [Tekst] / E.V. Kamyshnykova // Aktual'ni problemy ekonomiky. Ekonomika ta upravlinnya pidpryyemstvamy: zb. nauk. pr. - Vyp. 11 (101). - K., 2009. - S. $77-82$. ;

4. Sorokina, I.V. Teoretyko-metodolohichni aspekty formuvannya systemy ekonomichnoyi bezpeky pidpryyemstva [Tekst] / I.V. Sorokina // Aktual'ni problemy ekonomiky. Ekonomika ta upravlinnya pidpryyemstvamy: zb. nauk. pr. - Vyp. 12 (102). - K., 2009. - S. $114-122$;

5. Havva, V.M. Obgruntuvannya hospodars'kykh rishen' i otsinyuvannya ryzykiv [Tekst] / V.M. Havva, T.P. Razdymakha. - Kh.: KhAY, 2008. -272 s.;

6. Vartanyan, V.M. Modely, metody y ynstrumental'nye sredstva podderzhky prynyatyya reshenyy v naukoemkom vysokotekhnolohycheskom proyzvodstve [Tekst]: monohr. / V.M. Vartanyan, B.B. Stelyuk, M.A. Hlovanova, Y.V. Dronova. - Kh.: YD «YNZhEK», 2009. - 224s.

\section{ЕО НОВОСТИ АВТОМАТИЗАЦИИ}

\section{Открытие новейшей лаборатории Мехатроники и робототехники}

16 октября 2014 в рамках очередной Международной научно практической конференции «Информационные технологии и автоматизация - 2014» на базе Одесской национальной академии пищевых техенологий и при поддержке Мирового лидера по производству промышленной пневматики итальянской компании Camozzi прошло торжественное открытие новейшей и уникальной в своем роде научно - исследовательской лаборатории Мехатроники и робототехнии. В лаборатории сконцентрировано уникальное оборудование, которое можно встретить только на наиболее современных предприятиях. Открытие лаборатории по праву займет особое место в истории развития ВУЗа.

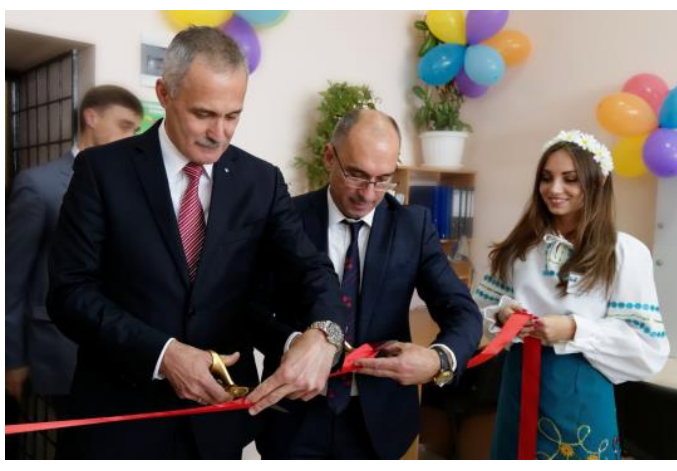

(https://www.youtube.com/watch?v=TC-POMOu9uA) 